\title{
Discoidin Domain Receptor 1
}

\section{Isoform Expression and Potential Functions in Cirrhotic Human Liver}

Sunmi Song, Nicholas A. Shackel, Xin M. Wang, Katerina Ajami, Geoffrey W. McCaughan, and Mark D. Gorrell

From the Centenary Institute and the A.W. Morrow Gastroenterology and Liver Centre, Royal Prince Alfred Hospital and the Sydney Medical School, University of Sydney, New South Wales, Australia

Discoidin domain receptor 1 (DDR1) is a receptor tyrosine kinase that binds and is activated by collagens. Transcriptional profiling of cirrhosis in human liver using a DNA array and quantitative PCR detected elevated mRNA expression of DDR1 compared with that in nondiseased liver. The present study characterized DDR1 expression in cirrhotic and nondiseased human liver and examined the cellular effects of DDR1 expression. mRNA expression of all five isoforms of DDR1 was detected in human liver, whereas DDR1a demonstrated differential expression in liver with hepatitis $C$ virus and primary biliary cirrhosis compared with nondiseased liver. In addition, immunoblot analysis detected shed fragments of DDR1 more readily in cirrhotic liver than in nondiseased liver. Inasmuch as DDR1 is subject to protease-mediated cleavage after prolonged interaction with collagen, this differential expression may indicate more intense activation of DDR1 protein in cirrhotic compared with nondiseased liver. In situ hybridization and immunofluorescence localized intense DDR1 mRNA and protein expression to epithelial cells including hepatocytes at the portal-parenchymal interface and the luminal aspect of the biliary epithelium. Overexpression of DDR1a altered hepatocyte behavior including increased adhesion and less migration on extracelular matrix substrates. DDR1a regulated extracellular expression of matrix metalloproteinases 1 and 2 . These data elucidate DDR1 function pertinent to cirrhosis and indicate the importance of epithelial cell-collagen interactions in chronic liver injury. (Am J Pathol 2011, 178:1134-1144; DOI: 10.1016/j.ajpath.2010.11.068)

Liver cirrhosis is a leading cause of death by infectious disease worldwide. Hepatic fibrosis is a wound-healing response to liver injury, with morphologic features of extracellular matrix (ECM) remodeling, contraction, and "scarring." As a response to tissue injury, activated stellate cells synthesize more and altered ECM..$^{1,2}$ In liver fibrosis, collagen and noncollagenous components of the ECM are increased as much as 10 -fold. ${ }^{3}$

Living cells need to sense and manage changes in ECM components in a highly orchestrated manner to generate appropriate cellular responses such as division, differentiation, survival, migration, and invasion. This process is mediated by many of the cell surface receptors of the family of receptor tyrosine kinases.

Discoidin domain receptors DDR1 and DDR2 constitute a subfamily of receptor tyrosine kinases and have been identified as nonintegrin receptors for collagen. DDR1 and DDR2 are differentiated from each other by their relative affinity for different types of collagens. DDR1 is activated by both fibrillar and nonfibrillar collagens (types I to V, VIII, and XI), whereas DDR2 is activated only by fibrillar collagens, in particular, types I and III. ${ }^{4,5}$ With prolonged exposure to collagen, DDR1 is processed into a soluble $54-\mathrm{kDa}$ extracellular $\alpha$-subunit and a $63-\mathrm{kDa}$

Supported by National Health and Medical Research Council of Australia (NHMRC) program grants 358398 and 571408 (G.W.M.). N.A.S., X.M.W., and K.A. received NHMRC postgraduate scholarships.

Accepted for publication November 15, 2010.

Supplemental material for this article can be found at $h$ ttp://ajp. amjpathol.org and at doi: 10.1016/j.ajpath.2010.11.068.

Current address of S.S.: Cell Transformation Unit, Children's Medical Research Institute, Westmead, NSW 2145, Australia; of X.M.W.: Westmead Millenium Institute, University of Sydney and Westmead Hospital, Westmead, NSW 2145 Australia.

Address reprint requests to Mark D. Gorrell, Ph.D., Centenary Institute, Locked Bag No. 6, Newtown, NSW 2042, Australia. E-mail: M.Gorrell@centenary.usyd.edu.au. 

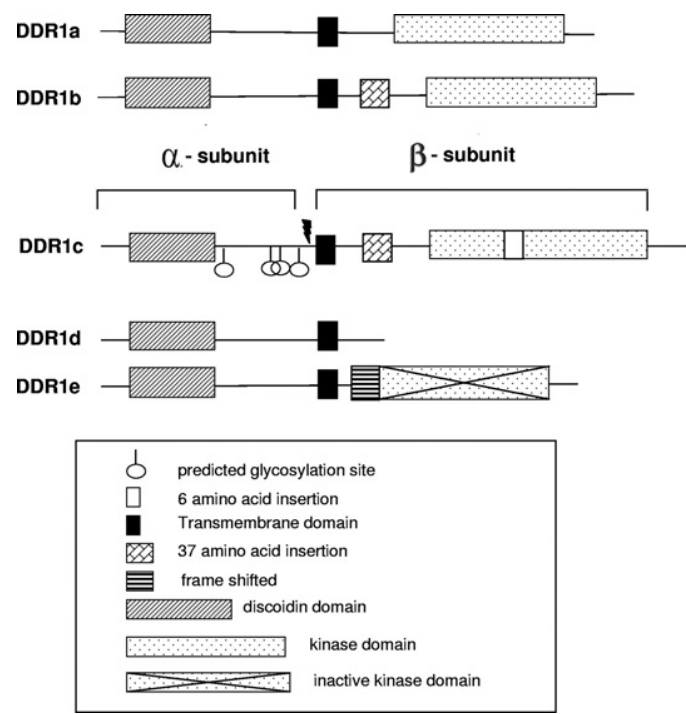

Figure 1. Schematic representation of the five isoforms of DDR 1 that have been identified in human liver. Isoforms $\mathrm{a}, \mathrm{b}$, and $\mathrm{c}$ are kinase active Isoforms $\mathrm{d}$ and e are kinase deficient from truncation or frame shift, respectively. On collagen-induced activation, DDR1 is cleaved at the cell surface (arrow), generating an extracellular $(\alpha)$ and an intracellular $(\beta)$ subunit.

membrane-bound $\beta$-subunit containing the cytoplasmic region. ${ }^{6-9}$ As a collagen receptor, DDR1 expression needs to be tightly regulated. DDR1 is selectively expressed in epithelial cells, and its expression is significantly increased in various tumors including mammary, ${ }^{10}$ ovarian, ${ }^{11}$ and esophageal ${ }^{12}$ carcinomas and in cirrhotic liver. ${ }^{13}$

At least five isoforms (named with suffixes a to e) are generated through alternative splicing of the kinase domain of the human DDR1 gene. ${ }^{6,7,14}$ Isoforms $\mathrm{a}, \mathrm{b}$, and c are kinase-active, whereas isoforms $d$ and e are kinasedeficient because of frame shift and truncation (Figure 1). A sixth isoform that lacks part of the extracellular domain has been described in rat testis. ${ }^{15}$ These isoforms exhibit differences in the extent of glycosylation, ${ }^{16}$ phosphorylation, ${ }^{6,17}$ protein interactions, ${ }^{18,19}$ and expression patterns and functions. ${ }^{17}$ DDR 1 regulates adhesion, ${ }^{17,20}$ migration, ${ }^{17,21-24}$ proliferation and apoptosis, $^{24,25}$ cell morphogenesis and differentiation, ${ }^{21,24}$ and ECM remodeling. ${ }^{26,27}$ These effects of DDR1 seem to be isoform-specific in different cell models, and have not been characterized in liver.

Transcriptional profiling of cirrhosis in human liver using a DNA array and quantitative real-time RT-PCR have enabled detection of elevated DDR1 mRNA expression by more than twofold in all types of cirrhotic liver tested (cirrhosis associated with autoimmune hepatitis $[\mathrm{AlH}]$, hepatitis B virus, primary biliary cirrhosis [PBC], and primary sclerosing cholangitis) compared with nondiseased liver using primers that bind to DDR1 isoforms $a, b$, and c $(n=4$ to 6$) .{ }^{13}$ These novel observations of increased DDR1 mRNA expression in cirrhotic liver suggest a potential role of DDR1 in liver fibrogenesis. The present study further characterized DDR1 expression in human liver and investigated functional effects of increased DDR1 expression in hepatocytes. Increased DDR1 expression by hepatocytes, leukocytes, and biliary epithe- lial cells of cirrhotic liver was observed. In addition, differing forms of DDR1 protein were detected in cirrhotic liver compared with nondiseased liver. In hepatocellular carcinoma Huh7 cells, DDR1a overexpression resulted in greater cell adhesion, specifically to collagen I, and less cell migration on ECM. Actin cytoskeletal arrangement remained unaffected by DDR1a overexpression. Extracellular but not intracellular expression of MMP1 and MMP2 were altered by DDR1a overexpression.

\section{Materials and Methods}

\section{RNA Extraction and cDNA Synthesis from Human Liver}

Total RNA was isolated from transplant-donor liver biopsy specimens $(n=8)$, end-stage Child-Pugh class C cirrhotic hepatitis $\mathrm{C}$ virus $(n=6), \mathrm{AlH}(n=4)$, and $\mathrm{PBC}(n=$ 6) tissue obtained at liver transplantation (Table 1), and reverse transcribed using Superscript III (Invitrogen Corp., Carlsbad, CA), as previously described. ${ }^{28}$ Tissue was obtained with consent in accordance with Australian Medical Research Council guidelines after approval by the institutional ethics committee.

Table 1. Patient Characteristics

\begin{tabular}{|c|c|c|c|c|}
\hline Identifier & Status & Cirrhosis & Sex & Age, yr \\
\hline ND 1 & Tx donor & - & Female & 22 \\
\hline ND 2 & Tx donor & - & Male & 13 \\
\hline ND 3 & Tx donor & - & NA & NA \\
\hline ND 4 & Tx donor & - & NA & NA \\
\hline ND 5 & Tx donor & - & Male & 18 \\
\hline ND 6 & Tx donor & - & NA & NA \\
\hline ND 7 & Tx donor & - & NA & NA \\
\hline Pt 1 & $\mathrm{AlH}$ & + & Female & 23 \\
\hline Pt 2 & $\mathrm{AlH}$ & + & Female & 17 \\
\hline $\mathrm{Pt} 3$ & $\mathrm{AlH}$ & + & Female & 32 \\
\hline Pt 4 & $\mathrm{AlH}$ & + & Female & 30 \\
\hline Pt 5 & $\mathrm{AlH}$ & + & Female & 25 \\
\hline Pt 6 & $\mathrm{AlH}$ & + & Female & 31 \\
\hline Pt 7 & $\mathrm{HCV}$ & + & Male & 44 \\
\hline Pt 8 & $\mathrm{HCV}$ & + & Female & 57 \\
\hline Pt 9 & HCV/alcohol & + & Male & 48 \\
\hline Pt 10 & $\mathrm{HCV}$ & + & Female & 61 \\
\hline Pt 11 & $\mathrm{HCV}$ & + & Male & 34 \\
\hline Pt 12 & $\mathrm{HCV}$ & + & Male & 48 \\
\hline Pt 13 & $\mathrm{HCV}$ & + & Female & 46 \\
\hline Pt 14 & $\mathrm{HCV}$ & + & Male & 59 \\
\hline Pt 15 & $\mathrm{HCV}$ & + & Female & 57 \\
\hline Pt 16 & PBC & + & Female & 66 \\
\hline Pt 17 & PBC & + & Female & 43 \\
\hline Pt 18 & PBC & + & Male & 49 \\
\hline Pt 19 & PBC & + & Female & 57 \\
\hline Pt 20 & PBC & + & Female & 61 \\
\hline Pt 21 & PBC & + & Female & NA \\
\hline Pt 22 & PSC & + & Male & 22 \\
\hline Pt 23 & $\mathrm{HCC}$ & + & Male & 53 \\
\hline Pt 24 & HBV & + & Male & 50 \\
\hline Pt 25 & Alcohol & + & Male & 54 \\
\hline
\end{tabular}

NA, data not available; ND, nondiseased liver; Pt, patient; Tx, transplant; +, present; -, absent. 
1136 Song et al

AJP March 2011, Vol. 178, No. 3

Table 2. PCR Primers

\begin{tabular}{|c|c|c|c|}
\hline Gene & Primer name & Sequence & ${ }^{\circ} \mathrm{C}$ \\
\hline DDR1 & F1359 & $5^{\prime}$-GGTGTTGGAAGAGGAGCTGA-3' & 64 \\
\hline DDR1 & R1524-1A & $5^{\prime}$-CCCACTGTAGGAGAGCCATT-3' & 63 \\
\hline DDR1 & Ex9F & 5'-TCATCTCTGATGTGGTGAACAA-3' & 63.2 \\
\hline DDR1 & R2055 & $5^{\prime}$-GAGCCTCGACATGATCTTCAC- $3^{\prime}$ & 63.8 \\
\hline DDR1 & $\mathrm{F} 2156 \mathrm{ex} 13$ & $5^{\prime}$-GATCTCGACTCCGCTTCA-3' & 61 \\
\hline DDR1 & $\mathrm{R} 2351 \mathrm{c} 6$ & $5^{\prime}-$ CTGGAGAACAAGGAGAAGC $-3^{\prime}$ & 59 \\
\hline DDR1 & DDR1e.R & 5'-TGGCTCTCTAGGACCTTGCT-3' & 63 \\
\hline DDR1 & DDR1deE.R & $5^{\prime}-$ AGGTGCACCAGAGCCATT- $3^{\prime}$ & 63.4 \\
\hline Aldolase B & Aldolase For & $5^{\prime}-$ CCTCGCTATCCAGGAAAAC- $3^{\prime}$ & 61.2 \\
\hline Aldolase B & Aldolase Rev & $5^{\prime}$-TTGTAGACAGCAGCCAGGAC- $3^{\prime}$ & 63.1 \\
\hline DDR1 & F534 & 5'-GCGGGTAGAGCTCTATGGCTGCCTCTGGAG-3' & 78.8 \\
\hline DDR1 & R1080 & $5^{\prime}$-GCTGAAGAGTAACCAGGGCCCCGCAAAGA-3' & 79.6 \\
\hline DDR1 & DDR1.EcoRI.F & $5^{\prime}$ - ATTTATGAATTCATCAGGAGCTATGGGACCAGG- $3^{\prime}$ & 73.4 \\
\hline DDR1 & DDR1.Kpnl.R & 5'-TATTAGGTACCCACACCGTGTTGAGTGCATCCT-3' & 75.8 \\
\hline DDR1 & \#2264tmt.F & 5'-AGCCGGAACCTCTTTGCTGGGGACTTTTTCCGTGTGCAGGGC-3' & 89.3 \\
\hline DDR1 & \#2264tmt.R & $5^{\prime}$-GCCCTGCACACGGAAAAAGTCCCCAGCAAAGAGGTTCCGGCT-3' & 89.3 \\
\hline DDR1 & \#2111.F & $5^{\prime}-$ CCCACCARCAGCTACCCAATGCTGCTGCATGTG-3' & 83.9 \\
\hline DDR1 & \#2111.R & 5'-CACATGCAGCAGCATTGGGTAGCTGATGGTGGG-3' & 83.9 \\
\hline
\end{tabular}

\section{Cell Lines}

The cell lines human embryonic kidney (HEK) 293T, human ovarian carcinoma 2008, human colon cancer HCT15, human lung adenocarcinoma A549, human breast cancer MCF7, human hepatic stellate cell LX2, human hepatoma Huh7, human epithelial colorectal adenocarcinoma $\mathrm{CaCO} 2$, human squamous cell carcinoma Colo16, human keratinocyte HaCaT, human Burkitt's lymphoma Raji, and human T-cell lymphoblast-like Jurkat were maintained in standard media with fetal calf serum.

\section{Real-Time RT-PCR}

DDR1 isoforms were detected at RT-PCR using primers (Table 2) and AmpliTaq Gold Polymerase (Applied Biosystems Inc., Foster City, CA) according to the manufacturer's instructions. Differential expression of DDR1a mRNA was quantified using a modification of published methods. ${ }^{28,29}$ All reactions were performed in duplicate using a sequence detector (Prism, model 7700; Applied Biosytems, Inc.), and were analyzed using sequence detector software (Prism, version.1.6.3; Applied Biosystems, Inc.).

\section{Immunocytochemical Staining and in Situ Hybridization}

Immunofluorescence, immunohistochemistry, and in situ hybridization have been described previously. ${ }^{28-31}$ Antibody concentration optima were CD45 (M0855, 1:100), CK7 (M0718, 1:143), CK18 (M7010, 1:143), and CK19 (M0772, 1:143) (all from DAKO Corp., Carpinteria, CA). Digoxigenin-labeled riboprobes were generated from a human DDR1 566-bp fragment (nucleotides 534 to 1080; GenBank accession No. AY335786) using a digoxigenin RNA labeling kit (Boehringer Mannheim Corp., Indianapolis, IN). Hybridization was on paraffin sections overnight at $42^{\circ} \mathrm{C}$. Flow cytometry has been described previously. ${ }^{32}$

\section{Western Blot Analysis}

Frozen liver tissue, $0.5 \mathrm{~g}$, was homogenized on ice in $2 \mathrm{ml}$ of PBS containing complete EDTA-free protease inhibitor cocktail (Roche Molecular Systems, Inc., Branchburg, $\mathrm{NJ})$. Cell debris was spun down, and $3 \mathrm{ml}$ of PBS containing protease and phosphatase inhibitor cocktails (Sigma-Aldrich, St Louis, MO) and $30 \mu \mathrm{L}$ of $\times 100$ deoxyribonuclease was added to the supernatant before centrifugation at $1000 \times g$ for 5 minutes. The supernatant was further centrifuged at $110,000 \times g$ for 75 minutes at $4^{\circ} \mathrm{C}$. Supernatant contained total cytosolic protein, and the pellet contained membrane-bound proteins. The cell membrane pellet was dissolved in $1 \mathrm{ml}$ of NP40 buffer (20 $\mathrm{mmol} / \mathrm{L}$ Tris- $\mathrm{HCl}, \mathrm{pH} 8.0 ; 137$ mmol/L NaCl; 10\% glycerol; $1 \%$ NP40, $2 \mathrm{mmol} / \mathrm{L}$ EDTA) with agitation for 1 hour at $4^{\circ} \mathrm{C}$. Samples were run on precast $7 \%$ or $3 \%$ to $8 \%$ gradient polyacrylamide electrophoresis gels (Invitrogen Corp.) and transferred to an Immobilon-PVDF membrane (Millipore Corp., Bedford, MA). DDR1 protein expression was detected using two monoclonal antibodies: rabbit anti-DDR1 (C-20) (1:500 dilution; Santa Cruz Biotechnology, Inc., Santa Cruz, CA) or ab5508 (1:500 dilution; Abcam PLC, Cambridge, MA) followed by horseradish peroxidase-conjugated goat anti-rabbit IgG (1:1000 dilution; Dako Corp.). These two antibodies to DDR1, C20 and ab5508, recognize the $\mathrm{C}$-terminus and the $\mathrm{N}$-terminus, respectively. Visualization of immune complexes after Western blot analysis has been described previously. ${ }^{33}$

\section{Constructs and Mutagenesis}

Full-length human DDR1a cDNA was inserted in-frame upstream of $C$-terminal green fluorescent protein (GFP) in the expression vector pEGFP-N1 (BD Biosciences, Clontech Laboratories, Palo Alto, CA). This full-length DDR1a insert was prepared via PCR using a full-length DDR1a cDNA (clone ID 5262509; Open Biosystems, Inc., Hunts- 

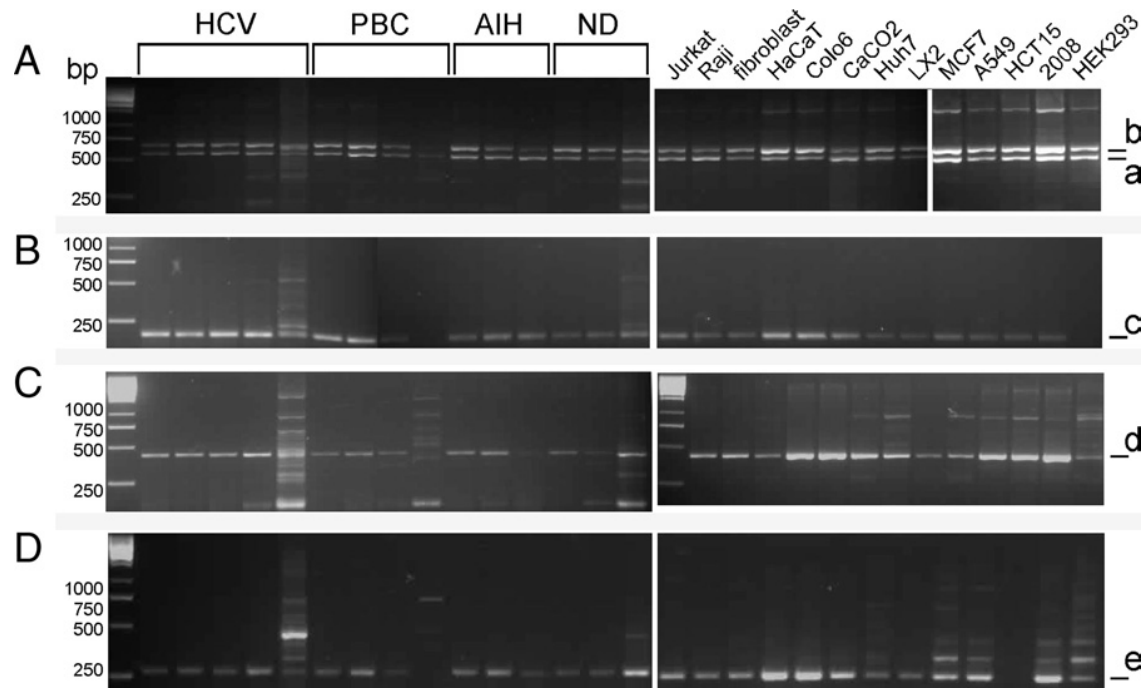

Figure 2. DDR1 isoforms in human liver and cell lines. A:, The two bands at 568 bp (a) and 680/698 bp (b) represent DDR1a and DDR1b/c, respectively. B:, The 125-bp band (c) of isoform $\mathrm{c}$ was detected in all samples except one live with PBC and the HEK293 cell line. C:, The 433-bp band (d) represents DDR1d. D:, DDR1e amplicon of $176 \mathrm{bp}$ (e) was detected in all samples except one PBC sample and the HCT15 cell line. HCV: lanes 1 to 5 represent patients $8,10,11,7$, and 9, respectively. PBC: lanes 6 to 9 represen patients $18,17,20$, and 21, respectively. AIH: lanes 10 to 12 represent patients 4,5 , and 6 , respectively. Nondiseased liver samples in lanes 13 to 15 represent nondiseased 5, nondiseased 1 , and nondiseased 4 .

ville, $A L)$ as the $P C R$ template with Advantage 2 Polymerase Mix (BD Biosciences, Clontech Laboratories). Cycles were $95^{\circ} \mathrm{C}$ for 10 minutes $\left(95^{\circ} \mathrm{C}\right.$ for 30 seconds, $58.3^{\circ} \mathrm{C}$ for 40 seconds, $68^{\circ} \mathrm{C}$ for 3 minutes 30 seconds) times 35 , $68^{\circ} \mathrm{C}$ for 5 minutes, and $11^{\circ} \mathrm{C}$ indefinitely. To generate a kinase-inactive mutant form of DDR1, three tyrosine phosphorylation sites at the kinase domain (amino acid positions 755,759 , and 760 ) were mutated to phenylalanine using point mutation primers 2264tmt.F and 2264tmt.R (Table 2). These residues are conserved residues of tyrosine kinase domains of trkA, trkB, and trkC. ${ }^{16}$ In addition, Y759 (equivalent to Y798 in DDR1b) is important for DDR1 interaction with $\mathrm{SH} 2$ affecting Stat3 tyrosine phosphorylation. ${ }^{34}$ The identities of all plasmid inserts were verified by complete sequencing.

\section{Cell Adhesion and Migration Assays}

Cell adhesion and migration assays were performed according to published methods. ${ }^{32,35}$ For cell adhesion, $6 \times$ $10^{5}$ Huh7 cells in $1 \mathrm{ml}$ were incubated for 20 minutes on plastic coated with $10 \mu \mathrm{g} / \mathrm{ml}$ of rat-tail collagen I (SigmaAldrich), human fibronectin (Sigma-Aldrich), or Matrigel (BD Biosciences Discovery Labware, Bedford, MA). The percentages of GFP-positive cells in adherent and nonadherent populations were obtained using flow cytometry. ${ }^{32,35}$

For transwell cell migration, overnight-serum-starved Huh7 cells were placed in the upper chamber at a density of $7.5 \times 10^{5} / \mathrm{ml}, 1 \mathrm{ml}$ per insert. The lower side of the transwell filter was coated with collagen I, fibronectin, or Matrigel. The lower chamber contained $2 \mathrm{ml}$ of Huh7conditioned medium with $1 \%$ fresh fetal calf serum, with or without hepatocyte growth factor at $20 \mathrm{ng} / \mathrm{ml}$ (R\&D Systems, Inc., Minneapolis, MN). Cells were allowed to migrate for about 36 hours. The percentages of fluorescent cells in the upper and lower chambers were obtained using flow cytometry.

\section{Phalloidin Staining}

Transfected cells were incubated overnight on 12-well slides (Trace Biosciences, Ltd., Sydney, Australia) coated with collagen I, fibronectin, Matrigel, or elastin. Cells on the slide were then formalin-fixed and permeabilized with $0.1 \%$ Triton $\mathrm{X} 100$, and treated with Phalloidin Alexa Fluor 594 (Molecular Probes, Invitrogen Corp.) at $0.5 \mathrm{U}$ per well for 20 minutes at room temperature, washed, and mounted with DAPI. Images were acquired using an Olympus FluoView FV 1000 confocal microscope (Olympus America, Inc., Center Valley, PA).

\section{Statistical Analysis}

Each experiment was repeated three to six times. Results are given as mean (SD). Differences between groups were analyzed using the nonparametric test one-way analysis of variance. $P<0.05$ was considered significant.

\section{Results}

\section{Detection of All Five Isoforms of DDR1 in Human Liver}

DDR1 has five isoforms that have distinct biological roles. RT-PCR detection of DDR1 isoforms in $\mathrm{AlH}, \mathrm{PBC}, \mathrm{HCV}$, and nondiseased human liver, as well as in 12 different cell lines, are shown in Figure 2. Amplification with the F1359-R2055 primer pair produced two bands, at 568 and 680 or $698 \mathrm{bp}$, representing isoform a and isoform $\mathrm{b}$ or $c$ ( $b$ or $c$ or a mixture of isoforms $b$ and $c$ ) in all but one sample (Figure 2A). The exception was a liver with PBC in which only isoform a at $568 \mathrm{bp}$ was detected. The upper band is likely a mixture of $680 \mathrm{bp}$ and $698 \mathrm{bp}$ amplicons because this 18-bp difference was not separated in 3\% agarose gels. However, the presence of DDR1c transcripts in these samples was confirmed in another RTPCR reaction with a primer pair specific for DDR1c, 


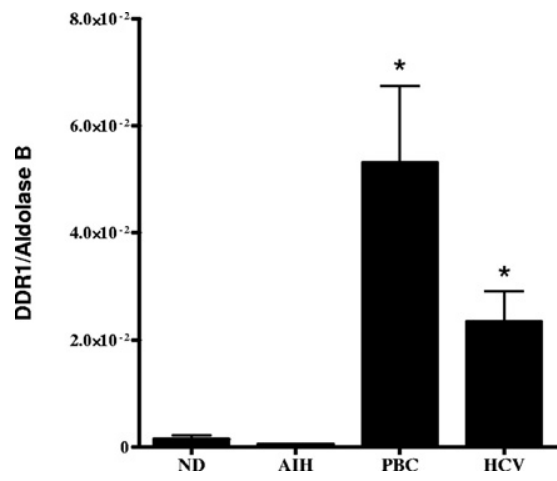

Figure 3. Human liver DDR1a mRNA. DDR1a expression was significantly greater in PBC-infected livers (patients 16 to 19) and HCV-infected livers (patients 11 to 14) compared with nondiseased (nondiseased 1 , nondiseased 2 , nondiseased 5 , and nondiseased 6 ) and AIH (patients 1, 2 , 4 , and 6) liver samples. " $P<0.05$. Relative gene copies per microgram of total RNA was measured using real-time RT-PCR, and was converted to a DDR1-aldolase B ratio.

F2156ex13, and R2351c6 (Figure 2C). Primer pair Ex9.F and DDR1de.R successfully amplified isoform d in all of the samples, and isoform e was detected by amplification with its specific primer pair, EX9F and DDR1e.R. Isoform e was detected in all samples except in one liver with $\mathrm{AlH}$ and the HEK293 cell line cDNA. Sequencing of bands confirmed their identities.

Real-time RT-PCR analysis revealed that DDR1a expression was significantly greater in PBC- and HCV-infected liver compared with samples of nondiseased liver and liver with AlH (Figure 3). Previously, increased DDR1 mRNA (pool of isoforms a, b, and c) has been reported in all cirrhotic liver tested compared with nondiseased liver. ${ }^{13}$ In the present study, no significant increase in DDR1a expression was detected in liver with $\mathrm{AlH}$ compared with nondiseased liver (Figure 3), which suggests that the expression of isoform $\mathrm{b}$ or $\mathrm{c}$ might contribute more than isoform a to the overall increase in DDR1 expression in liver with $\mathrm{AlH}$.

\section{DDR1 mRNA Localization}

To determine which intrahepatic cells express DDR1 mRNA, in situ hybridization was followed by epithelial cell immunostaining using anti-CK18. DDR1 mRNA was observed in hepatocytes at the portal-parenchymal interface and in biliary epithelial cells in the septum (Figure 4). The biliary epithelial cells included atypical reactive ductules at the septum-parenchyma interface. Atypical reactive ductules (also called "ductular reaction") are characterized by no or poorly defined lumina, lined by immature biliary cells with a relatively large and oval nucleus. ${ }^{36,37}$ DDR1 mRNA expression was also detected in some small CK18negative cells in the septum (Figure 4).

\section{DDR1 Immunolocalization}

Immunohistochemistry was performed on cryosections of nondiseased and cirrhotic human liver to compare the level of expression of DDR1 protein and its intrahepatic localization. A similar pattern of immunostaining for DDR1 was observed in HCV- (Figure 4, I and J), PBC-, HBV-, and AlH-associated cirrhosis (data not shown). The hepatic bile canalicular domain of hepatocytes and biliary epithelium were immunopositive for DDR1 in both nondiseased and $\mathrm{HCV}$-associated cirrhotic liver; however, staining was more intense in cirrhotic liver (Figure 4, I and J).

To identify DDR1 protein-expressing cells in human cirrhotic liver (PBC, HBV, and $\mathrm{AlH}$ ), sections were double stained for DDR1, and the cell type specific marker pro-
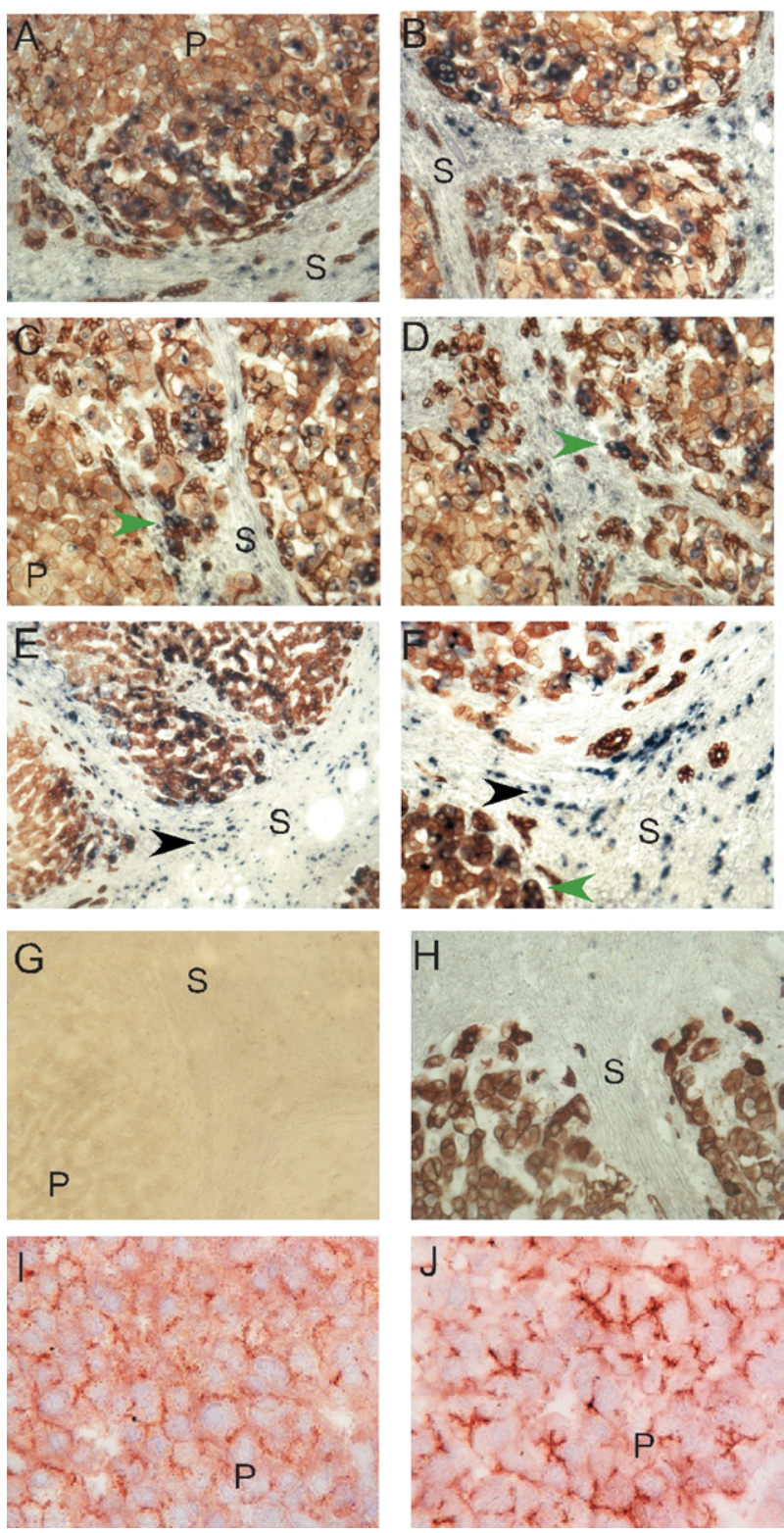

Figure 4. Localization of DDR1 in cirrhotic liver sections at in situ hybridization and immunostaining. A-H: After DDR1 in situ hybridization, paraffin sections were immunoperoxidase-stained for CK18. DDR1 mRNA was detected in CK18-immunopositive epithelial cells, in particular, hepatocytes at the edge of cirrhotic nodules and reactive bile duct cells (green arrowheads). Some small nonepithelial cells in the septum (black arrowheads) demonstrated DDR1 mRNA expression. Sense DDR1 riboprobe negative control before (G) and after (H) CK18 staining. P, parenchyma; S, septum. $\mathbf{I}$ and $\mathbf{J}$ : Cryosections of human liver were immunoperoxidase-stained with anti-DDR1 antibody C20. DDR1 immunostaining in HCV-associated cirrhotic liver (J) was more intense than in nondiseased liver (I). Original magnification: $\mathbf{A}-\mathbf{D}$ and $\mathbf{F}-\mathbf{J}, \times 200 ; \mathbf{E}, \times 100$ 


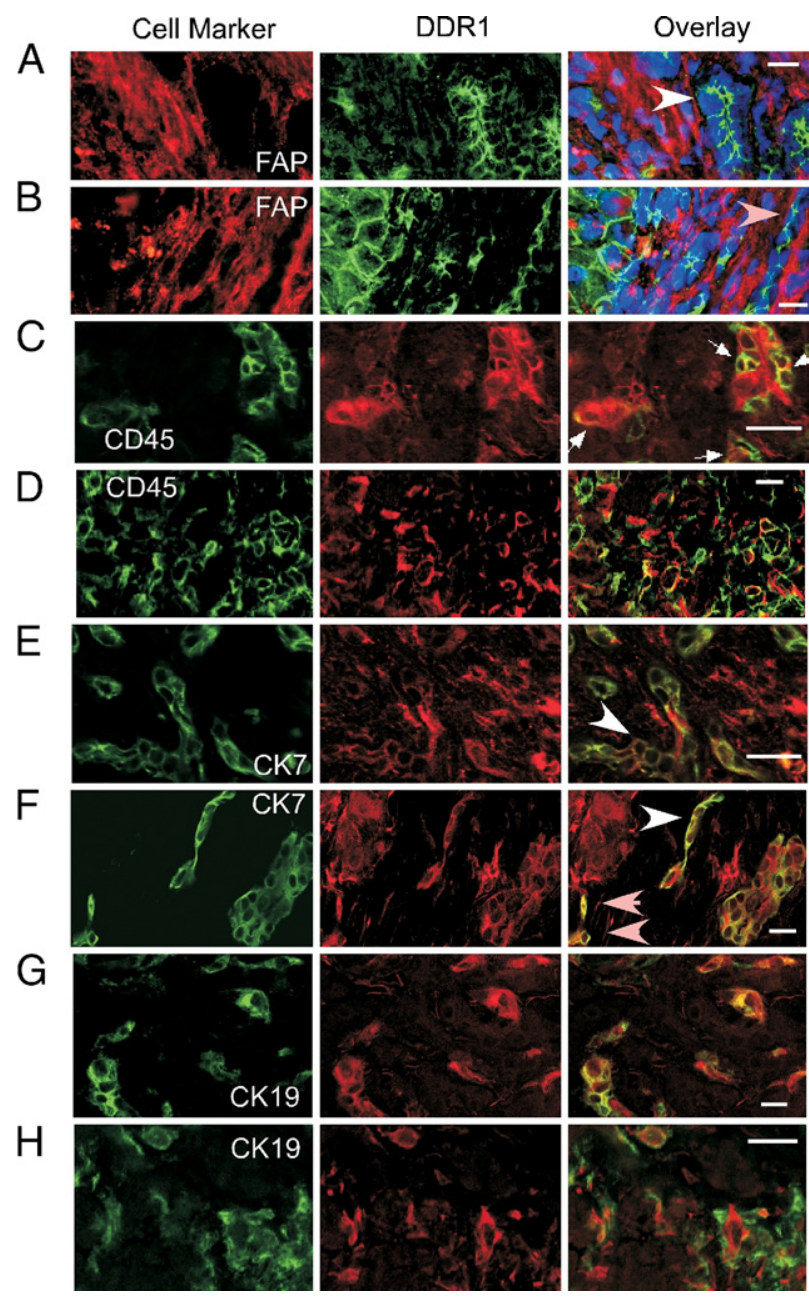

Figure 5. Immunofluorescence localization of DDR1 protein. Human cirrhotic liver sections were double stained for DDR1 and fibroblast activation protein (A and B), CD45 (C and D), CK7 (E and F), or CK19 (G and H). Left and center panels:, Single-color images; right panel:, overlaid images. Scale bar $=20 \mu \mathrm{mol} / \mathrm{L}$. A and B:, DDR1 protein (green) was detected primarily on epithelial cells, which are negative for fibroblast activation protein (FAP) and include parenchymal hepatocytes at the portal-parenchymal interface, bile ductules (white arrowhead), and the luminal aspect of reactive bile duct cells (pink arrowheads). Three-color overlay with nuclei stained blue using DAPI (patient 25). C and D:, Parenchymal and septal CD45-positive leukocytes (green) expressed DDR1 (red; arrows; patient 19). $\mathbf{E}$ and F:, Some cells in the septum were double positive for CK7 (green) and DDR1 (red). These cells were in ductular reactions (arrows) and as single cells near the ductular reactions (pink arrowheads). E:, Patient 15. F: Patient 19. G and H:, CK19 (green) and DDR1 (red) double immunostaining occurred in many bile duct cells within the parenchyma $(\mathbf{G})$ and at the portal-parenchymal interface $(\mathbf{H})$. Ductular reactions and some single cells were positive for both DDR1 and CK19 (patient 22).

teins fibroblast activation protein for activated stellate cells, ${ }^{38}$ CD45 for leukocytes, and CK19 and CK7 for biliary epithelial cells. DDR1 expression was on fibroblast activation protein-negative cells (Figure 5). Consistent with DDR1 mRNA expression, intense DDR1 protein expression was detected in parenchymal hepatic cells, especially in hepatocytes at the portal-parenchymal interface and in bile ductule epithelial cells. DDR1 protein was observed on entire cell surfaces of many hepatocytes at the portal-parenchymal interface, whereas it was detected on the luminal surface of bile duct cells and the apical domain of parenchymal hepatocytes. Some leu- kocytes were immunopositive for DDR1. DDR1 was localized to the same cell types in each liver disease sample examined (PBC, HCV, hepatitis B virus, and AIH) (Figure 5, and data not shown).

Epithelial cells of reactive bile ductules in the septum, cells in a structure that seemed to be a ductular reaction, and occasional single cells near these ductular reactions were immunopositive for both DDR1 and CK7 (Figure 5, E and F). Some biliary epithelial cells in the parenchyma septum and around the septum-parenchyma interface were double positive for CK19 and DDR1 (Figure 5, G and $\mathrm{H}$ ).

\section{Different DDR1 Protein Forms in Cirrhotic versus Nondiseased Liver}

Molecular forms of DDR1 protein in human liver were examined using Western blot analysis. The variation in band intensities between patients (Figures 6 and 7) was consistent in replicate gels. The two anti-DDR1 antibodies used were $\mathrm{C20}$, raised against the $\mathrm{C}$-terminus of DDR1 (intracellular domain), and ab5508, which binds to the $N$-terminus of DDR1 (extracellular domain) (Figure 6). DDR1 isoforms a, b, and c can be detected using C20 antibody; however, isoforms $d$ and e would not be recognized because of a frame shift at the tyrosine kinase domain (Figure 1). Ab5508 antibody can detect all five isoforms because they all have the same extracellular domain. Immunoblot analyses of membrane preparations

\section{A Membrane extract}

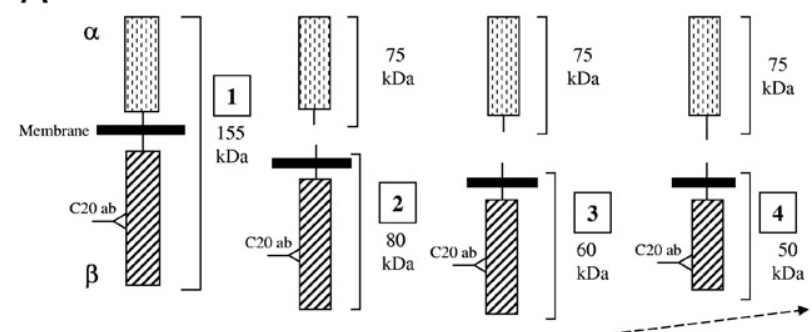

B Soluble extract

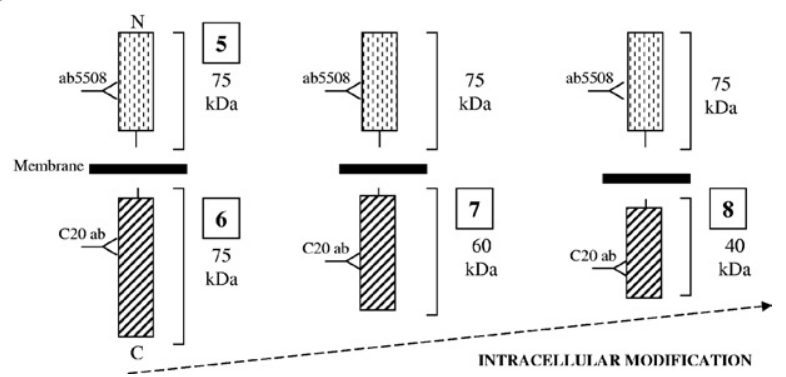

Figure 6. Schema of possible cleavage points that generated DDR1 peptides that were detected with two separate antibodies, ab5508 and C20. These antibodies recognize the $N$-terminus and $C$-terminus of DDR1, respectively. A: In preparation of cell membranes, $\mathrm{C} 20$ antibody can detect the full-length DDR1 of $\sim 155 \mathrm{kDa}$, [1] $\beta$-subunits or a membrane-bound DDR1 fragment of $\sim 80 \mathrm{kDa}[2]$ and further cleaved to yield membrane-bound $\beta$-subunits of $\sim 50$ to $60 \mathrm{kDa}[3$ and 4]. B:, In the water-soluble cell extracts, ab5508 antibody can detect the $\alpha$-subunit and $N$-terminal fragment of DDR1 after cleavage ( 75 $\mathrm{kDa},[5])$, whereas the $\mathrm{C} 20$ antibody can detect $\beta$-subunits that are soluble due to intracellular cleavage [6] and fragments of [6] that retain the C20 antibodybinding site [7 and 8]. Such peptides could be $\sim 40$ to $60 \mathrm{kDa}$. 
(Figure 7A) and soluble preparations (Figure 7B) of protein extracts from human liver stained with $\mathrm{C} 20$ antibody differed.

In the membrane preparation, bands running at approximately 130 and $150 \mathrm{kDa}$ were more intense in nondiseased (lanes 6-8) compared with cirrhotic liver (Figure 7A). These bands probably represent full-length DDR1 $(150 \mathrm{kDa})$ and partially degraded DDR1 (100 and $130 \mathrm{kDa}$ ). DDR1 peptides of approximately 80, 60, and $40 \mathrm{kDa}$ were present in cirrhotic liver but not in nondiseased liver. These smaller bands probably represent the $\beta$-subunit of DDR1 and fragments of the $\beta$-subunits (Figure $6 \mathrm{~A}$ ). Despite using protease inhibitors in the preparation of protein extracts, partial degradation of DDR1
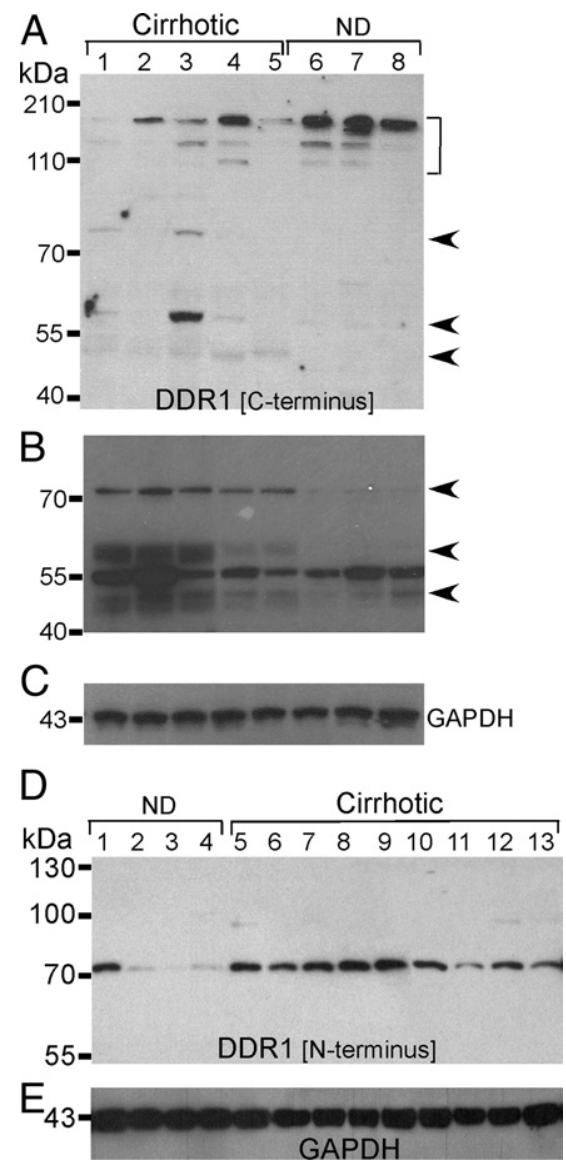

Figure 7. Different forms of DDR1 proteins detected in cirrhotic and nondiseased liver. Membrane (A) and soluble (B and $\mathbf{C}$ ) liver extracts underwent immunoblot analysis using polyclonal antibody C20, which binds to the $C$-terminus of DDR1. Membrane extract bands running at greater than 100 $\mathrm{kDa}$ (bracket) were more intense in nondiseased (lanes 6 to 8) than cirrhotic (lanes 1 to 5 ) liver, and bands at $\sim 80,60$, and $50 \mathrm{kDa}$ (arrows) in cirrhotic liver were not detected in nondiseased liver. From soluble extracts (B), intense bands at $\sim 75,60$, and $50 \mathrm{kDa}$ (arrows) in cirrhotic liver were weak or not detected in nondiseased liver. GAPDH (glyceraldehyde-3-phosphate dehydrogenase) was the loading control for soluble extracts (C). Lane 1, patient 13; lane 2, patient 10; lane 3, patient 23; lane 4, patient 22; lane 5 , patient 6; lane 6, nondiseased liver 5; lane 7, nondiseased liver 2; and lane 8 , nondiseased liver 1. D:, Western blot analysis of soluble aqueous extracts of human liver with a polyclonal rabbit DDR1 antibody raised against the $\mathrm{N}$-terminus of DDR1 (ab5580). The soluble $\mathrm{N}$-terminal fragment of DDR1 (75 $\mathrm{kDa}$ band) was detected in all liver samples but was more intense in samples of cirrhotic liver (lanes 5 to 13; patients 12, 6, 24, 3, 17, 5, 4, 3, and 19) than nondiseased liver (lanes 1 to 4 ; patients nondiseased 4 , nondiseased 1 , nondiseased 2, and nondiseased 5). E:, Equal loading of lanes is exhibited by GAPDH immunoblot.

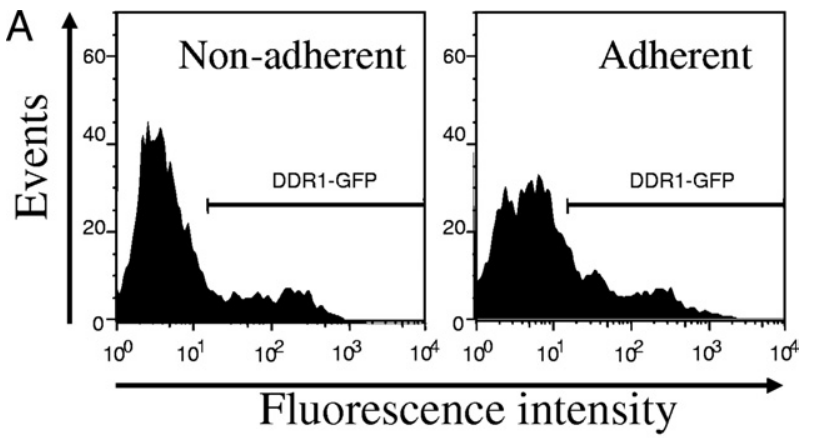

B

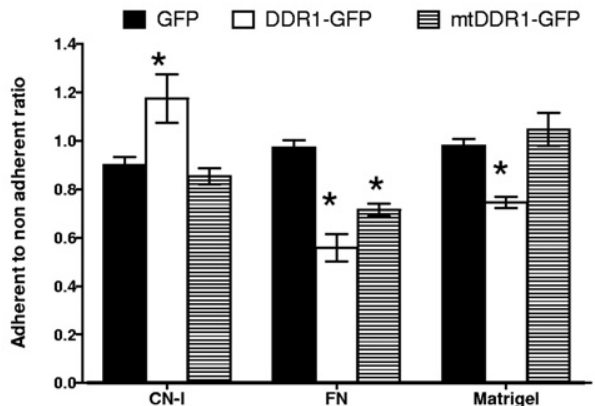

Figure 8. In vitro adhesion of DDR1 and mtDDR1-GFP ovexpressing Huh7 cells on ECM components. A: Fluorescent cells adherent and nonadherent to ECM substrate-coated plates were enumerated at flow cytometery. B: DDR1-GFP protein overexpression increased cell adhesion on collagen (CN-I), but decreased adhesion on fibronectin (FN) and Matrigel. Cell adhesion is expressed as a ratio of the percentage of GFP-positive cells in the adherent cell population to the percentage of GFP-positive nonadherent cells. At least 3000 adherent cells were counted for each data point. Representative of five experiments. ${ }^{*} P<0.05$ compared with GFP transfection.

protein occurred. This partial degradation or fragmentation of a protein might occur during the protein extraction procedure or as a result of intracellular proteolysis in vivo.

In the soluble extracts, the 75-, 60-, and 50-kDa bands were readily detected using $\mathrm{C} 20$ antibody in cirrhotic but not in nondiseased liver (Figure 7B). The 75-kDa band may represent the $\beta$-subunit cleaved intracellularly in vivo, and thereby solubilized. The 60- and 50-kDa bands are likely remnants of $\beta$-subunits that have been further processed intracellularly in vivo (Figure 7B).

These results suggest that DDR1 is shed more readily in cirrhotic than in nondiseased liver. To further examine this hypothesis, the $\alpha$-subunit of DDR1 was detected in the soluble fraction with ab5508 antibody for comparison in cirrhotic versus nondiseased liver (Figure 7D). The 75-kDa band, representing the $\alpha$-subunit, was detected in all samples; however, this band was much weaker in three of four nondiseased liver samples (Figure 7D, lanes 2-4) than in any of the cirrhotic liver samples tested (Figure 7D, lanes 5-13).

\section{Adhesion and Migration of Huh7 Cells Overexpressing DDR1}

Typically, more than $80 \%$ of Huh7 cells were detectably transfected with GFP, and more than $30 \%$ with the DDR1GFP and mtDDR1-GFP constructs (see Supplemental Figure S1 at $h$ ttp://ajp.amjpathol.org). Cells overexpressing DDR1-GFP but not mtDDR1-GFP exhibited increased 


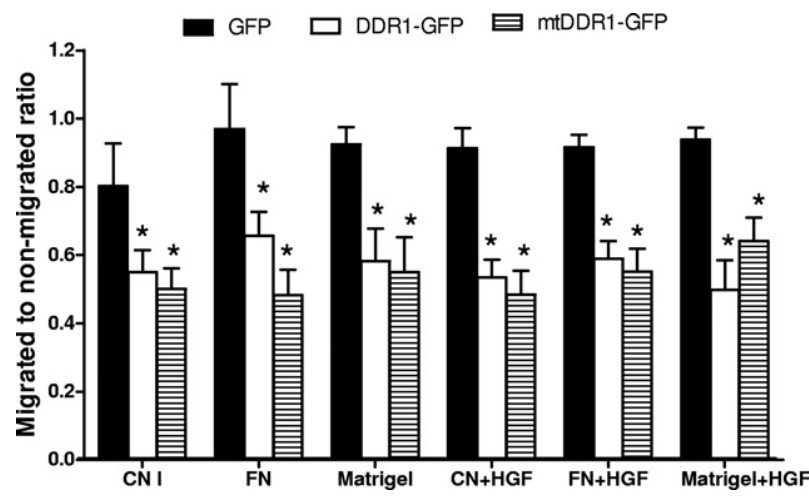

Figure 9. Decreased cell migration by DDR1 overexpressing cells. In vitro cell migration of Huh7 cells transfected with GFP control, DDR1-GFP, or mtDDR1-GFP across transwells toward ECM components with or without HGF. Ratios are the percentage of fluorescent cells in the migrated cell population to the percentage of fluorescent nonmigrated cells. This experiment was repeated three times. Mean $(\mathrm{SD}){ }^{*} P<0.05$ for all comparisons of GFP with wild-type DDR1 or mutant DDR1

adhesion on plastic coated with collagen I compared with cells expressing GFP alone $(P<0.05)$ (Figure 8), consistent with the reported role of DDR1 as a collagen binding receptor. Cells expressing DDR1-GFP exhibited reduced adhesion on fibronectin and Matrigel, and cells expressing mtDDR1-GFP also demonstrated reduced adhesion on fibronectin- but not on Matrigel-coated plastic. Huh7 cells transfected with DDR1-GFP or mtDDR1GFP exhibited less migration, compared with vector control, toward collagen I, fibronectin, or Matrigel with or without HGF (Figure 9). DDR1 or mtDDR1 overexpression did not alter actin cytoskeleton in Huh7 cells plated on slides coated with collagen I (see Supplemental Figure S2 at http://ajp.amjpathol.org), fibronectin, or Matrigel (data not shown). In addition, neither DDR1 nor mtDDR1 co-localized with phalloidin-labeled actin cytoskeleton. There was generally less mtDDR1-GFP on the cell surface (Figure S1) and some mtDDR1-GFP in aggresomelike bodies (Figure S2), which might have impaired binding by cell surface mtDDR1-GFP to collagen while retaining effects of DDR1 on migration that are perhaps initiated by cytoplasmic DDR1 or have a lower threshold of action.

\section{MMPs in Transfected Cells}

Analysis of intracellular MMP1, MMP2, and MMP3 expression using flow cytometry demonstrated no difference between GFP-, DDR1-GFP-, and mtDDR-GFPtransfected cells (see Supplemental Figure S3 at $h t t p: / /$ ajp.amjpathol.org). However, because these MMPs are secreted and regulated extracellularly, their expression levels were examined in Huh7 cell culture supernatants taken from the transfected cells (transfection efficiencies similar to those observed in Figure S1). Because DDR1mediated regulation of MMPs may require DDR1 activation or interaction with collagen, the cells were treated using collagen. At Western blot analysis, only the latent form of MMP1 was detected (60 kDa) in all samples, but was less intense in the culture supernatants of DDR1GFP- and mtDDR1-GFP-transfected cells compared with the GFP control (Figure 10A), which suggests that MMP1 expression was down-regulated by DDR1. Similarly, MMP2 levels were greater in GFP control than in DDR1transfected cultures (Figure 10B). However, after prolonged collagen exposure, the MMP2 active form (66 $\mathrm{kDa}$ ) was more readily detected in DDR1- than in GFPtransfected cultures; thus, DDR1 may have caused increased MMP2 activation. At 40 hours of exposure to collagen I, the MMP2 latent form was undetectable in all three groups, indicating either down-regulation or, more probably, activation.

\section{Discussion}

The present study investigated DDR1, which is a nonintegrin receptor for collagen and receptor tyrosine kinase, in liver cirrhosis. Findings of in vitro and in vivo experiments suggest dysregulation of DDR1 expression and function in the processes of liver injury.

Increased DDR1 mRNA expression has been reported in cirrhotic liver compared with nondiseased liver using transcriptional profiling using a DNA array of human cirrhosis. ${ }^{13}$ That study confirmed DDR1 mRNA up-regulation using a primer pair that binds to isoforms $a, b$, and $c$ and demonstrated that DDR1 transcript abundance was greater by more than twofold in all cirrhotic liver tested compared with nondiseased liver. In the present study, mRNA expression of all five isoforms was detected in human liver, and it was demonstrated that isoform a was differentially expressed in HCV- and PBC-infected livers compared with nondiseased livers or $\mathrm{AlH}$-infected livers. The basis of this differential expression is unknown. Intense DDR1 mRNA and protein expression was localized to epithelial cells and some leukocytes. Shed fragments
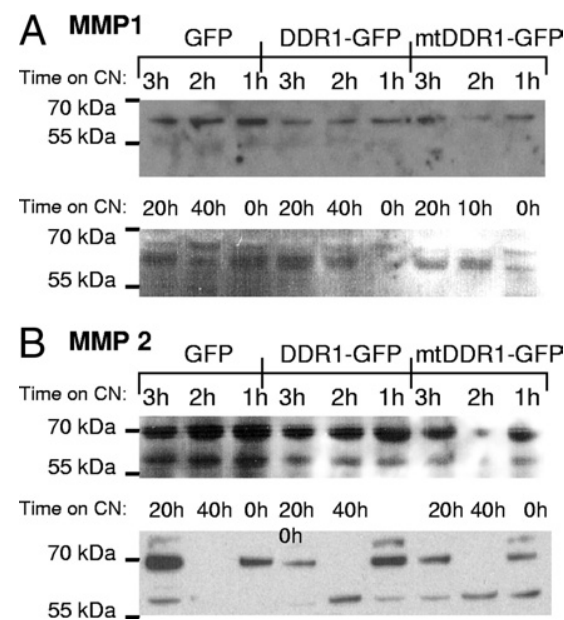

Figure 10. MMP1 and MMP2 regulation by DDR1-GFP overexpression. Transfected Huh7 cells were incubated with CN-I, $10 \mu \mathrm{g} / \mathrm{ml}$, for the times indicated. The cell culture supernatant underwent immunoblot analysis for secreted MMP1 (A) and MMP2 (B). The latent MMP1 band at $60 \mathrm{kDa}$ was weaker from DDR1-GFP- and mtDDR-GFP-transfected cells than from the GFP control. Both latent and active forms of MMP2 were detected at 72 and $66 \mathrm{kDa}$, respectively. In general, the latent MMP2 band was more intense from the GFP-transfected cells than from the DDR1- and mtDDR1-GFPtransfected cells, and the active form was more readily detected in DDR1 than in control GFP cultures. Equal quantities of total protein, $80 \mu \mathrm{g}$, were loaded into each lane. These data are representative of two experiments. 
of DDR1 protein were more abundant in cirrhotic compared with nondiseased liver. DDR1a overexpression in the Huh7 cell line increased adhesion specifically to collagen I and lessened mobility on ECM.

In tumors, DDR1 is expressed in epithelial tumor cells, whereas DDR2 expression is confined to mesenchymal stromal cells. ${ }^{6}$ DDR2 is expressed by activated hepatic stellate cells, the key fibrogenic mesenchymal cells in liver, and promotes MMP2-mediated proliferation and invasion by hepatic stellate cells. ${ }^{39,40}$ DDR1 was observed in hepatic epithelial cells but not in hepatic stellate cells. In cirrhotic human liver, hepatocytes at the portal-parenchymal interface are often swollen and lack polarity. ${ }^{41}$ Loss of cell polarity on some hepatocytes in cirrhotic liver, in particular those at the portal-parenchymal interface, seemed to result in unpolarized trafficking of DDR1, as also occurs with the apical marker dipeptidyl peptidase IV. ${ }^{42}$ Both DDR1 and dipeptidyl peptidase IV bind to ECM components, which emphasizes the importance of this function for hepatocytes.

The hepatic progenitor cell (HPC) markers CK7 and CK19 revealed that DDR1 expression was frequently observed in ductular reactions in which oval cells or HPCs usually reside. Moreover, some individual DDR1-expressing oval cells, which are potentially HPCs, were observed near ductular reactions. This novel localization of DDR1 expression in cells that are probably HPCs elucidates the recent detection of DDR1 mRNA in human and rat $\mathrm{HPCs}^{43,44}$ and deserves further investigation as to whether DDR1 expression has a role in differentiating HPCs into hepatocytes or bile duct cells.

Some CD45-positive DDR1-positive leukocytes were observed, consistent with other reports of DDR1 expression by leukocytes, in particular, macrophages. ${ }^{45}$ Liver cirrhosis involves inflammation including leukocyte infiltration, which requires leukocyte-ECM interactions. DDR1 is important in facilitating leukocyte migration. ${ }^{45}$ Migration of leukocytes in a tissue microenvironment requires efficient interaction of the cells with the components of ECM. Integrins have a major role in facilitating this interaction; however, data from the present study together with recent reports demonstrate the importance of DDR1 in facilitating leukocyte migration.

To our knowledge, this is the first study to report DDR1 protein size in human liver. A preponderance of smaller molecular forms of DDR1 proteins was observed in cirrhotic liver samples compared with nondiseased liver, with some individual variation between patients. From the membrane preparations, strong bands of approximately 150,130 , and $100 \mathrm{kDa}$ and less intense bands of approximately 60 and $40 \mathrm{kDa}$ were detected in nondiseased liver. In contrast, the smaller forms were more readily detected in cirrhotic liver. The $150-\mathrm{kDa}$ band is probably the full-length receptor, whereas the smaller 80-, 60-, and $40-\mathrm{kDa}$ bands are likely to be $\beta$-subunits and processed fragments of $\beta$-subunits of DDR1 (Figure 6). After prolonged activation of DDR1b, it becomes processed into a soluble $54-\mathrm{kDa}$ extracellular $\alpha$-subunit and a $62-\mathrm{kDa}$ membrane-bound $\beta$-subunit incorporating the cytoplasmic region in human mammary carcinoma cells. ${ }^{8}$ The $62-k D a \beta$-subunits are converted into smaller fragments.
Inasmuch as cell line characteristics result in differences in molecular sizes of DDR $1,{ }^{7}$ full-length DDR1, detected at $150 \mathrm{kDa}$ in human liver, may produce $80-\mathrm{kDa} \beta$-subunits and 70-kDa $\alpha$-subunits. The 60- and 40-kDa bands detected in the cirrhotic liver samples may be membrane-bound peptides of DDR1 that underwent intracellular modification but retained the C20 epitope (Figure 6). Moreover, from the soluble-protein preparation, antibody ab5508, which binds to the extracellular domain of DDR1, detected $70-\mathrm{kDa}$ bands that are likely to be $\alpha$-subunits of DDR1. Both antibodies detected more shed forms of DDR1 in cirrhotic than nondiseased liver. These data likely reflect increased DDR1 activation, which can cause shedding and increased DDR1-mediated signaling, in cirrhotic compared with nondiseased liver. Furthermore, depending on the rate of DDR1 dissociation from the bound collagen and the degradation of the shed DDR1 ectodomain, it is possible that the DDR1 ectodomain continues to exert further effects such as inhibition of the fibrillogenesis of collagen. ${ }^{46}$ The present study is the first to report the presence of more shed DDR1 ectodomain in cirrhotic liver compared with nondiseased liver.

Many studies have demonstrated the involvement of DDR1 in cell adhesion and migration; however, effects on cell behavior of overexpression of DDR1 vary with cell type. DDR1a overexpression in Huh7 cells resulted in more adhesion specifically to collagen I but less migration toward collagen I, fibronectin, and Matrigel. Increased adhesion to collagen by DDR1-overexpressing Huh7 cells suggests that the predominant interaction of hepatocyte DDR1 with collagen is binding. Removing the three known potential tyrosine phosphorylation sites of DDR1a (mtDDR1-GFP) ablated this DDR1-dependent increased cell binding to collagen but did not influence migration, which suggests that DDR1a might act through different mechanisms, and perhaps indirectly, to regulate binding versus migration in the assay system used. When hepatocytes are surrounded by excess collagen, as in cirrhotic liver, particularly at the parenchymal-septum interface, increased DDR1 expression at the cell surface of hepatocytes would enhance DDR1-mediated cell ECM binding to collagen I. Increased cell adhesion to collagen and reduced cell motility may be a necessary mechanism to compensate for the loss of cell-cell contact, which is typically observed in damaged hepatocytes at the portalparenchymal interface. ${ }^{41}$ The MMP data suggest a role for DDR1 in regulation of extracellular MMP1 and MMP2 in hepatocytes, and this role was independent of the three mutated tyrosines of DDR1. However, the overall effect of increased MMP2 and decreased MMP1 after prolonged collagen exposure might not have significantly influenced the apparent dominant effect of collagen adhesion under the assay conditions.

The biological significance of increased DDR1 expression in cirrhotic liver is largely unknown. Findings of the present study demonstrate that DDR1 is expressed by hepatocytes, leukocytes, and biliary epithelial cells, which may all contribute to increased DDR1 expression in cirrhotic liver. More shed fragments of DDR1 were detected in cirrhotic than in nondiseased liver, which suggests increased DDR1 activation in cirrhotic liver. In- 
creased DDR1a expression affected basic cell behavior in hepatocytes including increased adhesion and immobilization of the cells on ECM substrates. These data elucidate DDR1 function pertinent to cirrhosis and point to the importance of epithelial cell-ECM interactions in chronic liver injury.

\section{Acknowledgments}

We thank Ms. Tsun-Wen Yao for technical assistance. Elastin was supplied by Professor Anthony Weiss, Ph.D. (School of Molecular and Microbiol Biosciences, University of Sydney).

\section{References}

1. Arthur MJ, Friedman SL, Roll FJ, Bissell DM: Lipocytes from normal rat liver release a neutral metalloproteinase that degrades basement membrane (type IV) collagen. J Clin Invest 1989, 84:1076-1085

2. Winwood PJ, Schuppan D, Iredale JP, Kawser CA, Docherty AJ, Arthur MJ: Kupffer cell-derived 95-kd type IV collagenase/gelatinase $\mathrm{B}$ : characterization and expression in cultured cells. Hepatology 1995, 22:304-315

3. Schuppan D: Structure of the extracellular matrix in normal and fibrotic liver: collagens and glycoproteins. Semin Liver Dis 1990, 10: $1-10$

4. Ikeda K, Wang LH, Torres R, Zhao H, Olaso E, Eng FJ, Labrador P, Klein R, Lovett D, Yancopoulos GD, Friedman SL, Lin HC: Discoidin domain receptor 2 interacts with Src and Shc following its activation by type I collagen. J Biol Chem 2002, 277:19206-19212

5. Vogel W, Gish GD, Alves F, Pawson T: The discoidin domain receptor tyrosine kinases are activated by collagen. Mol Cell 1997 $1: 13-23$

6. Alves F, Vogel W, Mossie K, Millauer B, Hofler H, Ullrich A: Distinct structural characteristics of discoidin I subfamily receptor tyrosine kinases and complementary expression in human cancer. Oncogene 1995, 10:609-618

7. Perez JL, Jing SQ, Wong TW: Identification of two isoforms of the Cak receptor kinase that are coexpressed in breast tumor cell lines. Oncogene 1996, 12:1469-1477

8. Vogel WF: Ligand-induced shedding of discoidin domain receptor 1. FEBS Lett 2002, 514:175-180

9. Slack BE, Siniaia MS, Blusztajn JK: Collagen type I selectively activates ectodomain shedding of the discoidin domain receptor 1 : involvement of Src tyrosine kinase. J Cell Biochem 2006, 98:672684

10. Johnson JD, Edman JC, Rutter WJ: A receptor tyrosine kinase found in breast carcinoma cells has an extracellular discoidin I-like domain. Proc Natl Acad Sci USA 1993, 90:5677-5681

11. Laval S, Butler R, Shelling AN, Hanby AM, Poulsom R, Ganesan TS: Isolation and characterization of an epithelial-specific receptor tyrosine kinase from an ovarian cancer cell line. Cell Growth Differ 1994, 5:1173-1183

12. Nemoto T, Ohashi K, Akashi T, Johnson JD, Hirokawa K: Overexpression of protein tyrosine kinases in human esophageal cancer. Pathobiology 1997, 65:195-203

13. Shackel NA, McGuinness PH, Abbott CA, Gorrell MD, McCaughan GW: Insights into the pathobiology of hepatitis C virus-associated cirrhosis: analysis of intrahepatic differential gene expression. Am J Pathol 2002, 160:641-654

14. Alves F, Saupe S, Ledwon M, Schaub F, Hiddemann W, Vogel WF: Identification of two novel, kinase-deficient variants of discoidin domain receptor 1: differential expression in human colon cancer cell lines. FASEB J 2001, 15:1321-1323

15. Mullenbach E, Walter L, Dressel R: A novel discoidin domain receptor 1 (Ddr1) transcript is expressed in postmeiotic germ cells of the rat testis depending on the major histocompatibility complex haplotype. Gene 2006, 372:53-61
16. Di Marco E, Cutuli N, Guerra L, Cancedda R, De Luca M: Molecular cloning of trkE, a novel trk-related putative tyrosine kinase receptor isolated from normal human keratinocytes and widely expressed by normal human tissues. J Biol Chem 1993, 268:24290-24295

17. Kamohara H, Yamashiro S, Galligan C, Yoshimura T: Discoidin domain receptor 1 isoform- $\alpha$ (DDR1alpha) promotes migration of leukocytes in three-dimensional collagen lattices. FASEB J 2001, 15:2724-2726

18. Foehr ED, Tatavos A, Tanabe E, Raffioni S, Goetz S, Dimarco E, De Luca M, Bradshaw RA: Discoidin domain receptor 1 (DDR1) signaling in PC12 cells: activation of juxtamembrane domains in PDGFR/DDR/ TrkA chimeric receptors. FASEB J 2000, 14:973-981

19. Vogel W: Discoidin domain receptors: structural relations and functional implications. FASEB J 1999, 13(Suppl):S77-S82

20. Curat CA, Vogel WF: Discoidin domain receptor 1 controls growth and adhesion of mesangial cells. J Am Soc Nephrol 2002, 13:26482656

21. Bhatt RS, Tomoda T, Fang Y, Hatten ME: Discoidin domain receptor 1 functions in axon extension of cerebellar granule neurons. Genes Dev 2000, 14:2216-2228

22. Hou G, Vogel W, Bendeck MP: The discoidin domain receptor tyrosine kinase DDR1 in arterial wound repair. J Clin Invest 2001, 107:727-735

23. Hou GP, Vogel WF, Bendeck MP: Tyrosine kinase activity of discoidin domain receptor 1 is necessary for smooth muscle cell migration and matrix metalloproteinase expression. Circ Res 2002, 90:1147-1149

24. Wang CZ, Hsu YM, Tang MJ: Function of discoidin domain receptor I in HGF-induced branching tubulogenesis of MDCK cells in collagen gel. J Cell Physiol 2005, 203:295-304

25. Vogel WF, Aszodi A, Alves F, Pawson T: Discoidin domain receptor 1 tyrosine kinase has an essential role in mammary gland development. Mol Cell Biol 2001, 21:2906-2917

26. Agarwal G, Mihai C, Iscru DF: Interaction of discoidin domain receptor 1 with collagen type 1. J Mol Biol 2007, 367:443-455

27. Ram R, Lorente G, Nikolich K, Urfer R, Foehr E, Nagavarapu U: Discoidin domain receptor-1a (DDR1a) promotes glioma cell invasion and adhesion in association with matrix metalloproteinase-2. J Neu rooncol 2006, 76:239-248

28. Seth D, Gorrell MD, Cordoba S, McCaughan GW, Haber PS: Intrahepatic gene expression in human alcoholic hepatitis. J Hepatol 2006 45:306-320

29. Huang XX, McCaughan GW, Shackel NA, Gorrell MD: Upregulation of pro-proliferative genes and the ligand/receptor pair placental growth factor and vascular endothelial growth factor receptor 1 in hepatitis $\mathrm{C}$ cirrhosis. Liver Int 2007, 27:960-968

30. Gorrell MD, Willis G, Brandon MR, Lascelles AK: Lymphocyte phenotypes in the intestinal mucosa of sheep infected with TrichostrongyIus colubriformis. Clin Exp Immunol 1988, 72:274-279

31. Yu DMT, Ajami K, Gall MG, Park J, Lee CS, Evans KA, McLaughlin EA, Pitman MR, Abbott CA, McCaughan GW, Gorrell MD: The in vivo expression of dipeptidyl peptidases 8 and 9. J Histochem Cytochem 2009, 57:1025-1040

32. Wang XM, Yu DMT, McCaughan GW, Gorrell MD: Fibroblast activation protein increases apoptosis, cell adhesion and migration by the LX-2 human stellate cell line. Hepatology 2005, 42:935-945

33. Ajami K, Abbott CA, Obradovic M, Gysbers V, Kähne T, McCaughan GW Gorrell MD: Structural requirements for catalysis, expression and dimerisation in the CD26/DPIV gene family. Biochemistry 2003, 42:694-701

34. Wang CZ, Su HW, Hsu YC, Shen MR, Tang MJ: A discoidin domain receptor 1/SHP-2 signaling complex inhibits alpha2beta1-integrinmediated signal transducers and activators of transcription 1/3 activation and cell migration. Mol Biol Cell 2006, 17:2839-2852

35. Yu DMT, Wang XM, McCaughan GW, Gorrell MD: Extra-enzymatic functions of the dipeptidyl peptidase (DP) IV related proteins DP8 and DP9 in cell adhesion, migration and apoptosis. FEBS J 2006, 273: 2447-2461

36. Tan J, Hytiroglou P, Wieczorek R, Park YN, Thung SN, Arias B, Theise ND: Immunohistochemical evidence for hepatic progenitor cells in liver diseases. Liver Int 2002, 22:365-373

37. Nowak G, Ericzon B, Nava S, Jaksch M, Westgren M, SumitranHolgersson S: Identification of expandable human hepatic progenitors which differentiate into mature hepatic cells in vivo. Gut 2005 , 54:972-979

38. Levy MT, McCaughan GW, Abbott CA, Park JE, Cunningham AM, Muller E, Rettig WJ, Gorrell MD: Fibroblast activation protein: a cell 
surface dipeptidyl peptidase and gelatinase expressed by stellate cells at the tissue remodelling interface in human cirrhosis. Hepatology 1999, 29:1768-1778

39. Mao TK, Kimura Y, Kenny TP, Branchi A, Gishi RG, Van de Water J, Kung HJ, Friedman SL, Gershwin ME: Elevated expression of tyrosine kinase DDR2 in primary biliary cirrhosis. Autoimmunity 2002, 35:521-529

40. Olaso E, Ikeda K, Eng FJ, Xu LM, Wang LH, Lin HC, Friedman SL: DDR2 receptor promotes MMP-2-mediated proliferation and invasion by hepatic stellate cells. J Clin Invest 2001, 108:1369-1378

41. Friedman SL: Molecular regulation of hepatic fibrosis, an integrated cellular response to tissue injury. J Biol Chem 2000, 275:2247-2250

42. Matsumoto Y, Bishop GA, McCaughan GW: Altered zonal expression of the CD26 antigen (dipeptidyl peptidase IV) in human cirrhotic liver. Hepatology 1992, 15:1048-1053
43. Jozefczuk J, Stachelscheid H, Chavez L, Herwig R, Lehrach H, Zeilinger K, Gerlach JC, Adjaye J: Molecular characterization of cultured adult human liver progenitor cells. Tissue Engineering Part C: Methods 2010, 16:821-834

44. Yovchev MI, Grozdanov PN, Joseph B, Gupta S, Dabeva MD: Novel hepatic progenitor cell surface markers in the adult rat liver. Hepatology 2007, 45:139-154

45. Matsuyama W, Watanabe M, Shirahama Y, Hirano R, Mitsuyama H, Higashimoto I, Osame M, Arimura K: Suppression of discoidin domain receptor 1 by RNA interference attenuates lung inflammation. J Immunol 2006, 176:1928-1936

46. Flynn LA, Blissett AR, Calomeni EP, Agarwal G: Inhibition of collagen fibrillogenesis by cells expressing soluble extracellular domains of DDR1 and DDR2. J Mol Biol 2010, 395:533-543 